\title{
Antibiogram Profile of Extraintestinal Pathogenic Escherichia Coli Clinical Isolates From Patients with Urinary Tractinfections at Kericho District Hospital, Kenya
}

\author{
David Cheruiyot ${ }^{1,2}$, Jackson Harold Odhiambo Onyuka ${ }^{2}$, Olivia Wesula Lwande ${ }^{3}$ \\ ${ }^{1}$ Kipkelion Sub-District Hospital P. O. Box 70 Kipkelion, Kenya \\ ${ }^{2}$ Department of Medical Laboratory Sciences, Mount Kenya University, School of Health Sciences, P.O. Box 342-0100 Thika, Kenya \\ ${ }^{3}$ Department of Medical Microbiology, Mount Kenya University, School of Medicine, P.O. Box 342-0100 Thika, Kenya
}

\begin{abstract}
Background: Escherichia coli is the common cause of primary urinary tract infections (UTIs). UTIs are the most common non-intestinal infection in women worldwide. Antimicrobial susceptibility testing provides information that allows physicians to select the 21 most appropriate antimicrobial agents for treating a specific infection. Methods: A cross-sectional study was conducted at Kericho District Hospital in and out patient's clinic between January and June 2015. A total of 133 urine samples were collected and used to investigate the prevalence of UTIs and to determine the antimicrobial profile of extraintestinal E. coli clinical isolates among in and out patients. UTIs were diagnosed using mid-stream urine culture on standard media. The bacterial isolates recovered were tested against trimethoprim-sulfamethoxazole, gentamycin, amikacin, ceftriaxone, ciprofloxacin, cefoxitin, cefepim, imipenem, ampicillin and amoxicillin-clavulanic acid using Kirby-Bauer disc diffusion technique. Data was entered in MS Excel spread sheet and analyzed by using SPSS version 20. Results: Among the 133 samples examined, 38\% had E. coli isolates with 64\% of them being from female patients compared to $36 \%$ from men. Approximately $73 \%$ of the isolates were resistant to trimethoprim-sulfamethoxazole and $91 \%$ resistant to amoxicillin clavulanic acid; $96 \%$ were susceptible to imipenem and $82 \%$ amikacine. E. coli showed high sensitivity to imipenem and amikacine but resistant to trimethoprin-sulfamethoxazole and amoxicillin-clavunic acid. Chi-square analysis indicated no association between gender of patient and pathogens isolate $(p=0.835)$. 37 Escherichia coli was the most prevalent clinical isolate $(p$ value $=0.905$ ) although there was 38 no association between the age of patient and pathogens isolated in patients indicating a possibility of an equal chance of being infected irrespective of age. Escherichia coli was the most prevalent causative organism, showing multi drug resistance pattern. Conclusion: Considering the relatively high rates of UTIs and drug resistance observed in this study, continued local, regional, and national surveillance is warranted. Imipenem and amikacine should be considered as drug of choice for empirical treatment of community acquired uncomplicated UTIs in patients in Kericho district hospital.
\end{abstract}

Keywords: Urinary tract infection, resistance, susceptible, antibiotic, bacteriuria

\section{Background}

Extraintestinal pathogenic $E$. coli (ExPEC), especially the uropathogenic $E$. coli (UPEC) pathotype, is most commonly associated with human infections due to $E$. coli outside the intestinal tract [1] and display enhanced ability to cause infection outside the intestinal tract, carry specific genetic determinants or virulence factors that are clustered on different pathogenicity islands [2]. Urinary tract infection is the most common non-intestinal infection in women worldwide [3]. The pathogens causing UTI are consistent across the globe. Uropathogenic E. coli (UPEC) is responsible for approximately $90 \%$ of urinary tract infections [4]. Urinary tract infections (UTIs) are among the most common infections that affect humans [5]. It is accounting for approximately $35 \%$ of nosocomial infections and also due to the frequency, recurrence and difficulty in eradication [6, 7]. Escherichia coli is the most predominant pathogen causing community and nosocomially-acquired urinary tract infections $[8,9,10]$. It is the most common pathogen, accounting for $85 \%$ of community-acquired and $50 \%$ of hospital-acquired infections [11].

UTIs (if untreated) can lead to serious obstetric complications, poor maternal and perinatal outcomes for example intrauterine growth restriction, caesarean delivery and preterm deliveries [12] in women. UTIs occur more frequently in developing countries among the low socioeconomic population. In the United States, UTI account for 8.3 million out-patient visits and 1 million hospitalizations annually. Masinde et al., [13] published a cross-sectional study from Tanzania in 2009 to determine the prevalence of UTI in both symptomatic and asymptomatic pregnant women. Of the 247 women in the 70 sample, $31.5 \%$ were symptomatic and of those women, $18 \%$ had bacteriuria. Interestingly, of 71 the $68.5 \%$ who were asymptomatic, $13 \%$ had bacteriuria as well [14].

UTIs are mainly caused by gram-negative organisms that include E. coli, Klebsiella, Proteus, and Pseudomonas and gram-positive bacteria, group B Streptococcus and Staphylococcus species $[15,16,17]$. These organisms are mainly from the external genitalia, vagina, the genital tract, rectum, and gastro-intestinal tract. Most organisms causing UTIs originate from the bowel flora. UTIs are a result of interactions between the uropathogen and host. Successful infection of the urinary tract is determined in part by the virulence factor of the bacterium, the inoculum size, and the inadequacy of the host defense mechanisms. The pathogens causing UTs are almost always predictable, with Escherichia 


\section{International Journal of Science and Research (IJSR) \\ ISSN (Online): 2319-7064 \\ Index Copernicus Value (2013): 6.14 | Impact Factor (2014): 5.611}

coli being the primary etiologic agent among both outpatients and inpatients accounting for $75 \%$ to $90 \%$ of urinary tract infection isolates $[18,19]$.

The pathogenesis of urinary tract infection involves ascending infection with coliform bacteria colonizing the perineum in susceptible women (80-90\% Escherichia coli, 5-10\% Staphylococcus saprophyticus with the remainder caused by Proteus and other Gram negative rods) [20]. While not generally considered a cause of significant mortality, UTI do represent an important cause of morbidity. Treatment of UTI varies with the type but is usually empirical because of the common spectrum of uropathogens. Drug resistance among bacteria causing UTI has increased since introduction to UTI chemotherapy [21, 22, 23, 24]. Regular analysis of bacterial flora is important to formulate updated guidelines [25]. The magnitude of UTI among in and out patients in Kericho district hospital is not known. Hence this study was designed to ascertain the prevalence and antibiogram profile of E. coli causing UTI at Kericho District Hospital.

\section{Methods}

\section{Study Design and Area}

This study was a cross sectional conducted at Kericho district hospital in and out patient's clinic between January to June 2015. The hospital is located in Kericho town, Kericho County which is approximately $300 \mathrm{Km}$ from Nairobi city, Figure 1. It is a major hospital in Kericho County. It has a population of 752,396 [26] and an area of $2,111 \mathrm{Km}^{2}$. According to Ministry of Health (MOH) report of 2013 the outpatient attending Kericho District Hospital per month is approximately 9,000 and inpatient per month is 1,350. Kericho District Hospital has a bed capacity of 250 patients.

\section{Urine Sample Collection}

A total of 133 midstream urine (MSU) samples were collected from study participants using a standard procedure. The midstream urine was collected using the techniques as was describe by Mwaka et al., (2011). Midway during voiding, without stopping the urinary stream, the patients plunged with the right hand a sterile wide mouth screw cap plastic bottle to collect about $30 \mathrm{mls}$ of MSU, and soon thereafter tightly close the bottles and hand them over to the study in the lab. The urine samples were placed in a cool box at $8{ }^{\circ} \mathrm{C}$ and transported to the microbiology laboratory within 2-4 hours of collection. All urine samples were turned up and down gently to allow proper mixing of urine and were analyzed immediately after they had been entered in a $\log$ book on arrival at the laboratory using dipstick (Mannheim GmbH, Germany) following manufacturer's instructions and culturing.

\section{Bacterial culture}

A standard calibrated wire loop with $4 \mathrm{~mm}$ internal diameter to remove $10 \mu \mathrm{l}$ of urine for inoculation onto Cystine Lactose Electrolyte Deficient (CLED) and MacConkey agar with crystal violet and 5\% sheep blood agar (Oxoid N.Y., USA). The streak method was used to uniformly spread the urine onto the agar surface before aerobically incubating the plates at $37^{\circ} \mathrm{C}$ for $18-24$ hours $[27,28]$. Colonies were counted after 24 hours of incubation. Plates with pure growth, and colonies $>10^{4} \mathrm{CFU} / \mathrm{ml}$ were further subjected for identification and sensitivity testing. Cut off point of $>10^{5}$ $\mathrm{CFU} / \mathrm{ml}$ was used to define UTIs. Identification of the microorganisms was done following standard procedures, with use of biochemical tests which included triple sugar iron agar, Simmon's citrate agar, lysine decarboxylase, urease, and motility tests [27], and where these could not give conclusive results, API 20 method Beckton Dickson USA [29] was used to identify the isolates.

\section{Anti-microbial susceptibility testing}

Sensitivity tests were done using the Mueller - Hinton agar (Fluka, Sigma-Aldrich), following the commercial disc diffusion techniques of Kirby - Bauer [30], against a panel of 10 antimicrobial agents. The antibiotic discs and their concentrations per disc (mg): Trimethoprimsulfamethoxazole $(1.25 / 23.75)$, representative antibiotics of aminoglycosides such as gentamicin (10), amikacin (10); quinolones such as ciprofloxacin (5); various cephalosporins such as ceftriaxone (30), cefoxitin (30), cefepim (30); from carbapenem antibiotics such as imipenem (10); penicillinlike antibiotics such as ampicillin (10) and amoxicillin clavulanic acid (20/10) (Oxoid, England). Escherichia coli ATCC 25922 was used as a control strain. Direct measurements of diameters of zones of inhibition of bacterial growths on agar plates to 10 antibiotics were done with a calibrated ruler. The breakpoint for antimicrobial drugs was based on the guidelines provided by the CLSI [31].

One to 5 discrete colonies from pure $E$. coli plate was picked with a standard wire loop from a purity plate, and emulsified into $5 \mathrm{mls}$ of sterile saline in a test tube. The saline was stirred with the loop to uniformly mix the colony in the saline. The turbidity of the saline was adjusted to match the standard McFarland 0.5, Biomerieux $®$. A sterile cotton swab on a stick was dipped in the colony-saline mixture, excess saline was squeezed out by pressing the swab against the test tube, and then the cotton swab gently applied onto the surface of the Mueller-Hinton agar. Six antibiotic impregnated discs were aseptically and gently placed on the agar surface, and the plates incubated at $37^{\circ} \mathrm{C}$ aerobically for 18 - 24 hours. The zones of inhibition diameters around each disc were measured using a ruler, and compared against the zone diameter interpretative standards recommended by the Clinical Laboratory Standard Institute [31]. Results were reported as sensitive or resistant, for each antibiotic used.

\section{Statistical analyses}

Data entry was done on excel spread sheet, and then exported to SPSS version 20 software for statistical analysis. Chi square test was used for comparisons between significant and non-significant bacteriuria, as well as to demonstrate associations between categorical variables. $\mathrm{P}$ value of 0.05 was used to determine level of statistical significance.

\section{Ethical Considerations}

This research project was approved by Mount Kenya University Ethical Review Committee and also by National Council for Science, Technology and Innovation (NACOSTI). Informed consent was obtained from each 


\section{International Journal of Science and Research (IJSR) ISSN (Online): 2319-7064 \\ Index Copernicus Value (2013): 6.14 | Impact Factor (2014): 5.611}

study participants before collecting urine specimens for laboratory analysis and confidentiality maintained.

\section{Results}

Prevalence of significant bacteriuria/urinary tract infections (UTI)

Of the 133 midstream urine samples cultured on CLED, $79.7 \%(106 / 133)$ of samples showed pure significant growth of bacteria, while $20.3 \%$ showed no bacterial growth after 72 hours of incubation.

\section{Uropathogens Isolated by Culture}

Five bacterial uropathogens were isolated from 106 midstream urine samples. Of these, up to 38 (35.8\%) had Escherichia coli, while others included Staphylococcus aureus 27\%, Klebsiella pneumonae 16\%, P. auruginosa and Proteus spp Figure 2, E. coli was the most prevalent.

\section{Antimicrobial Sensitivity Test Profiles}

A total of 38 uropathologic E. coli isolates $(\mathrm{n}=22)$ from females were tested for susceptibility to ten antimicrobials. In females (Table 1), the isolates were sensitive to imipene $21(95.5 \%)$ and amikacin $18(81.8 \%)$. Resistance to amoxicillin-clavulanic acid 20 (90.9\%), ampicillin 19 (86.4\%), gentamycin, cefoxitin and ceftriaxone 12 (54.4\%) respectively. There was a multidrug resistances observed in $E$. coli isolates which makes them unsuitable agents for empirical treatment for UTIs in the area of study. In males, a total of 16 isolates were tested against the ten antimicrobial agents. In males Table 2, imipenem 16 (100\%) was sensitive followed by amikacin 14 (87.5\%) and gentamicin $6(37.4 \%)$ respectively. A resistance pattern was observed, amoxicillinclavulanic acid and ampicillin $16(100 \%)$, followed by trimethoprin-sulfamethoxazole $15(93.75 \%)$, ciprofloxacin and cefoxitin $10(62.5 \%)$ ceftriaxone and cefepin $9(56.25 \%)$ which formed a tetramer resistance pattern. Imipenem and amikacin are sensitive to $E$. coli isolates either from females or males.

There was a high percentage of uropathogens in females $64.2 \%$ as compared to males $35.8 \%$ in the study area, there were more females than men. E. coli was still the most predominant uropathogen isolated in both females and males with $20.8 \%$ and $15.1 \%$ respectively and there was no association between gender of patient and pathogens isolated in patients and hence both genders can be infected and affected with pathogens, $\mathrm{p}=0.835$, Table 3 .

\section{Discussions}

Antibiotic resistance is a major clinical problem in treating infections caused by $E$. coli. The resistance to the antimicrobials has increased over the years and normal intestinal microbial flora became a reservoir for resistant genes. Though UTIs are common in both men and women, there is a large difference in UTI prevalence between them due to variety of factors [32]. Kebira et al., [33] opined that female had high UTIs than men caused by E. coli with $24 \%$ in Thika Level 5 Hospital, this was in agreement with our findings. Women are more susceptible to UTIs and have a $50 \%$ chance of experiencing at least one episode of UTI during their lifetime $[3,34]$. E. coli strains were the most common isolates. Similar findings have been reported in northern Tanzania with 202 68.4\%. [35]. A similar high proportion of E. coli was also reported in Sudan with 791.9\% [36] and Yemen [37] studies. In the present study, the predominant bacterial isolates were gram negative which 205 was similar to other findings [38] and Addis Ababa, Ethiopia [15]. Though E. coli is considered the most uropathogenic due to its virulence factors for colonization and invasion of the urinary epithelium [39], S. aureus can be also the most important uropathogen in the study area but it needs further study on its epidemiology and risk factors. Certain virulence factors like haemolysin production and presence of fimbriae in the E. coli may be associated with urovirulence [40].

Prescribing and giving antibiotics without testing antibiotic resistance pattern in developing countries including Kenya is a common problem for the development of drug resistance. In the present study, E. coli isolates were highly resistant to trimethoprin-sulfamethoxazole and amoxicillin-clavilanic acid in both genders. A similar finding was also reported in other studies [41, 42]. This high antibiotic resistance might be associated with previous exposure of the bacterial isolates to these antibiotics. In addition, in rural settings including the study area, use of antibiotics without proper prescription with health professionals is also a common practice. All these factors may be used as a risk factor for the development of antibiotic resistance especially for the commonly used ones. Furthermore, all of the E. coli isolates in this study were multidrug resistant. This may be due to the fact that the easy availability and indiscriminate use of commonly used drugs such as ampicillin, amoxicillinclavunic acid and trimethroprin-sulfamethoxazole may lead to an increase to resistance. Yismaw [19] and Astal et al., [43] have also reported resistance of E. coli to gentamicin, ciprofloxacin and ceftriaxone in the Gaza Strip respectively which is consistence with this study.

Kebira et al., [33] also stated that E. coli was 100\% resistant to trimethoprine -sulfamethoxazole in UTI cases in Thika, Kenya which was also consistent with the findings at Kericho District Hospital. Escherichia coli with its multidrug resistant strains has been found to be the commonest cause of UTI [44]. Imipenem was found to be the best effective antimicrobial in treatment of UTI in Kericho District hospital. Escherichia coli has been documented as the most important pathogen associated with urinary tract infections in many countries [45]. UTI in males, though rare, occurs in much less frequency [46] this too is consistent with our findings in this study area.

\section{Conclusion}

Based on our study findings, E. coli was found to be more prevalent in females than males. As reported previously, our study confirmed Escherichia coli to be a major uropathogen. The study further detected increasing resistance of Escherichia coli strains to trimethoprim- sulfamethoxazole. The results of this study highlight the need for continued surveillance of antimicrobial resistance among uropathogens causing UTI, so as to increase positive outcomes of clinical interventions. Imipenem and amikacine should be considered as drug of choice for empirical treatment of

\section{Volume 5 Issue 1, January 2016}




\section{International Journal of Science and Research (IJSR) ISSN (Online): 2319-7064 \\ Index Copernicus Value (2013): 6.14 | Impact Factor (2014): 5.611}

community acquired uncomplicated UTI in patients in Kericho district hospital.

Competing Interests: There is no conflict of interest.

\section{Author's Contribution}

DC: Conceived the study and participated in the design of the study, experimental setups, acquisition of data, data storage and management. Drafting of the manuscript.

JHOO: Participated in the study design, statistical analysis and interpretation, drafting of the manuscript and revising it critically.

OWL: Participated in the study design, critic the manuscript for intellectual content.

\section{Acknowledgment}

Special thanks to Ms. Philomena Chepkwony of Kericho district Hospital for the support and facilitating sample collection from Kericho hospital and the patients who provided samples for this study. We acknowledge the administrators of Kericho District hospital for allowing the study to be conducted in this institution and patients who participated in the study after consenting.

\section{References}

[1] Kohler CD, Dobrindt U. What defines extraintestinal pathogenic Escherichia coli? Int. J. Med. Microbiol 2011;301:642-7.

[2] Hacker J, Blum-Oehler G, Muhldorfer I, Tschape H. Pathogenicity islands of virulent bacteria: structure, function and impact on microbial evolution. Mol Microbiol 1997. 23: 1089-1097. doi: 10.1046/j.13652958.1997.3101672.x

[3] Dielubanza EJ, Schaeffer AJ. Urinary tract infections in women. Med Clin North Am. 2011;95:27-41.

[4] Todar K. Pathogenic E. coli. Online Textbook of Bacteriology. University of Wisconsin- Madison Department of Bacteriology 2007.

[5] Bergsten G, Wullt B, and Svanborg C. Escherichia coli, fimbriae, bacterial persistence and host response induction in the human urinary tract. Int $\mathrm{J}$ Med Microbiol. 2005 Oct; 295(6-293 7):487-502.

[6] Hooton T, Winter C, Tiu F, Stamm WE Randomized comparative trial and cost analysis of day antimicrobial regimens for treatment of acute cystitis in women. Nigeria J Microbiol 1995, 15:31-37.

[7] Ebie M, Kandakai O, Ayanbadejo J, Tanyigna KB. Urinary tract infections. Nigeria J. Microbiol 2001, 15(1):31-37.

[8] Foxman B. The epidemiology of urinary tract infection. Nat Rev Urol. 2010;7:653-60.

[9] Ejrnæs K. Bacterial characteristics of importance for recurrent urinary tract infections caused by Escherichia coli. Dan. Med. Bull.2011. 58: B4187.

[10] Momoh ARM, Orhue PO, Idonije OB, Oaikhena AG, Nwoke EO, Momoh AA. The antibiogram types of Escherichia coli isolated from suspected urinary tract infection samples. J. Microbiol. Biotech. Res., 2011, (3): 57-65

[11] Chung-Je Sue. Female lower unirnary tract infection. JTUA 2008. 19:12

[12] Mazor-Dray E, Levy A, Schlaeffer F, Sheiner E. Maternal urinary tract infection: is it independently associated with adverse pregnancy outcome? J Matern Fetal Neonatal Med 2009, 22(2):124-8.

[13] Masinde A, Gumodoka B, Kilonzo A, Mshana SE. Prevalence of urinary tract infection among pregnant women at Bugando Medical Centre, Mwanza, Tanzania. Tanzan J Health Res 2009. 11(3): 154-9.

[14] Akinloye O, Ogbolu DO, Akinloye OM, Terry AOA. Asymptomatic bacteriuria of pregnancy in Ibadan, Nigeria: a re-assessment. Br J Biomed Sci. 2006; 63(3): 109-12.

[15] Assefa A, Asrat D, Woldeamanuel YG, Hiwot Y, Abdella A, Melesse T. Bacterial profile and drug susceptibility pattern of urinary tract infection in pregnant women at Tikur Anbessa specialized hospital Addis Ababa, Ethiopia. Ethiopia Med J 2008; 46: 227 235.

[16] Okonko IO, Ijandipe LA, Ilusanya AO, DonbrayeEmmanuel OB, Ejembi J, Udeze AO, Egun OC. et la., Detection of Urinary Tract Infection (UTI) among pregnant women in Oluyoro Catholic Hospital, Ibadan, South-Western Nigeria, Malaysian Journal of Microbiology, 2010 6, no. 1, 16-24.

[17] Alemu AF, Moges Y, Shiferaw K, Tafess A, Kassu B, Agegn et al., . Bacterial profile and drug susceptibility pattern of urinary tract infection in pregnant women at University of Gondar Teaching Hospital, Northwest Ethiopia, BMC Research Notes 2012; 5, article no. 275 197.

[18] Nicolle LE. Epidemiology of urinary tract infection, Journal of Infection Medicine, 2001 18:153-162.

[19] Yismaw G, Abay S, Asrat D, Yifru S, Kassu A. Bacteriological profile and resistance pattern of clinical isolates from pediatric patients, Gondar University Teaching Hospital, Gondar, and North-East Ethiopia. Ethiopian Medical Journal; 48(4): 293- 300.

[20]Zalmanovici TA, Green H, Paul M, Yaphe J. Antimicrobial agents for treating uncomplicated urinary tract infection in women. Cochrane Database of Systemic Reviews, Issue 10.2010 Art. No.: $\quad$ CD007182. DOI: 10.1002/14651858.CD007182.pub2.

[21] Tseng MH, Lo WT, Lin WJ, Teng CS, Chu ML, Wang CC. Changing trend in antimicrobial resistance of pediatric uropathogens in Taiwa. Pediatric International. 2008;50:797-800.

[22] Haider H, Zehia N, Munir AA, Haider A. Risk factors of urinary tract infection in pregnancy. Journal of Pakistan Medical Association. 2010; 60:213-216.

[23] Bahadin J, Teo SSH, and Mathew S. Aetiology of community-acquired urinary tract infection and antimicrobial susceptibility patterns of uropathogens isolated. Singapore Medical Journal. 2011;52:415-420.

[24] Sood S, Gupta R. Antibiotic resistance pattern of community acquired uropathogens at a tertiary care hospital in Jaipur, Rajasthan. Indian Journal of Community Medicine. 2012;37:39-44

[25] Hisano M, Bruschini H, Nicodemo AC, Srougi M. 


\section{International Journal of Science and Research (IJSR) \\ ISSN (Online): 2319-7064 \\ Index Copernicus Value (2013): 6.14 | Impact Factor (2014): 5.611}

Uncomplicated Urinary Tract Infections in Women in a Sao Paulo Quaternary Care Hospital: Bacterial Spectrum and susceptibility 326 patterns. Antibiotics 2014, 3, 98-108; doi:10.3390/antibiotics 3010098

[26] Kenya National Bureau of Statistics. Census of 2009.

[27] Cheesbrough M. Laboratory Practice in Tropical Countries. Part 2 (C) Monica Cheesbrough 2000; 105 143.

[28] Chakraborty SP, KarMahapatra S, Bal M, Somenath R. Isolation Identification of ancomycin Resistant Staphylococcus aureus from Post Operative Pus Sample. Al Ameen J 300 Med Sci. 2011:4: 152-168.

[29] Hussein S. Bacterial identification by the Analytical Indexing system. American Society for microbiology 2010. http://www.microbelibrary.org/library

[30] Bauer AW, Kirby WMM, Sherris JC, Turch M. Antibiotic susceptibility testing by a standardized single disk method. Am J Clin Pathol.1966:45:493-6.

[31] Clinical and Laboratory Standards Institute. M100-S21 (M2) Disk Diffusion Supplemental Tables. CLSI 2011: Wayne, PA, USA.

[32]Lipsky BA. Urinary tract infection in men: epidemiology, Pathophysiology, diagnosis, and treatment. Ann Intern Med 2009, 110:138-150.

[33] Kebira AN, Ochola P, Khamadi SA. Isolation and Antimicrobial susceptibility testing of $E$. coli causing Urinary tract infections. Journal of Applied Sciences 2009: 22: 1320-1325. ISSN 1997-5902.

[34] Linhares I, Raposo T, Rodrigues A, Almeida A. Frequency and antimicrobial resistance patterns of bacteria implicated in community urinary tract infections: a ten-year surveillance study (2000-2009). BMC Infectious Diseases. 2013;13:19.

[35] Blomberg B, Jureen R, Manji KP, Tamim BS, Mwakagile DSM, Urassa WK, et al.,High rate of fatal cases of pediatric septicemia caused by Gram-negative bacteria with extended- spectrum beta-lactamases in Dar es Salaam, Tanzania. Journal of Clinical Microbiology 297 2005. 2, 745-749.

[36] Hamdan Z, Ziad AHM, Ali SK, Ishag A. Epidemiology of urinary tract infections and antibiotics sensitivity among pregnant women at Khartoum North Hospital. Ann Clin Microbiol Antimicrob 2011, 10(2):1-5.

[37] Al-Haddad A. Urinary tract infection among pregnant women in Al-. Mukalla district, Yemen. East Mediterr Health J 2005;11(3):505-511.

[38] Ferede G, Yismaw G, Wondimeneh Y Sisay Z. The prevalence and antimicrobial susceptibility pattern of bacterial uropathogens isolated from pregnant women. Eur J Exp 314 Biol 2012, 2(5):1497-1502.

[39] Sheffield J, Cunningham F. Urinary tract infection in women. Obstet Gynecol 2005, 106:1085-1092.

[40] Idonije OB, Momoh ARM, Orhue, PO, Oaikhena AG, Nwoke EO, Momoh AA. The antibiogram types of Escherichia coli isolated from suspected urinary tract infection amples. J. Microbiol. Biotech. Res., 2011, 1 (3):57-65.

[41] Asad U, Mohd S. Multiple drug resistance patterns in urinary tract infection patients in Aligarh. Biomed Res 2006. 17:179-181.

[42] Jazayeri A, Irajian G. Iran J Pathol 2009. 4:105-108.

[43] Astal Z. I ncreasing Ciprof loxacin Resistance Among Prevalent Urinary Tract Bacterial Isolates in Gaza St $r$ ip, Palestine. Journal of Biomedicine and Biotechnology; 2005. 3: 238-241

[44] Kariuki S, Revathi G, Corkill J, Kiiru J, Mwituria J, Mirza N, et al., Escherichia coli from communityacquired urinary tract infections resistant to fluoroquinolones and extended-spectrum beta-lactams. J. Infect. Dev. Ctries 2007. 1(3):257-62.

[45] Samra KS, Cenk S, Horu G, Mehmet G, Beril O. Increasing antimicrobial resistance of Escherichia coli isolates from community acquired UTI during 19982003 in Manisa Turkey Japan Journal of infectious disease 2005. 58:159-161.

[46] Mazzulli T. Antimicrobial resistance trends in common urinary pathogens. Canada Journal of Urology. 2001. 8 (Suppl 1): 2-5.

\section{Author Profile}

David Cheruiyot, is working at Kipkelion Sub-District Hospital P. O. Box 70 Kipkelion, Kenya, and also Master of Science in Medical Laboratory Sciences student in the Department of Medical Laboratory Sciences, Mount Kenya University, School of Health 256 Sciences, P.O. Box 342-0100 Thika, Kenya;

Dr. Jackson H. O. Onyuka, PhD Head of Department and Lecturer in the Department of Medical Laboratory Sciences, Mount Kenya University, School of Health Sciences, P.O. Box 342-0100 Thika, Kenya;

Dr. Olivia Wesula Lwande, PhD Lecturer in the Department of Medical Microbiology, Mount Kenya University, School of Medicine, P.O. Box 342-0100 Thika, Kenya. 


\section{International Journal of Science and Research (IJSR) \\ ISSN (Online): 2319-7064 \\ Index Copernicus Value (2013): 6.14 | Impact Factor (2014): 5.611}

Figure 1: Map of Kenya Showing Kericho County and the Sites of study, GIS -0.37159, 35.2801

Figure 2: Bacterial uropathogens isolated from 106 in and out patients

\section{Figures}

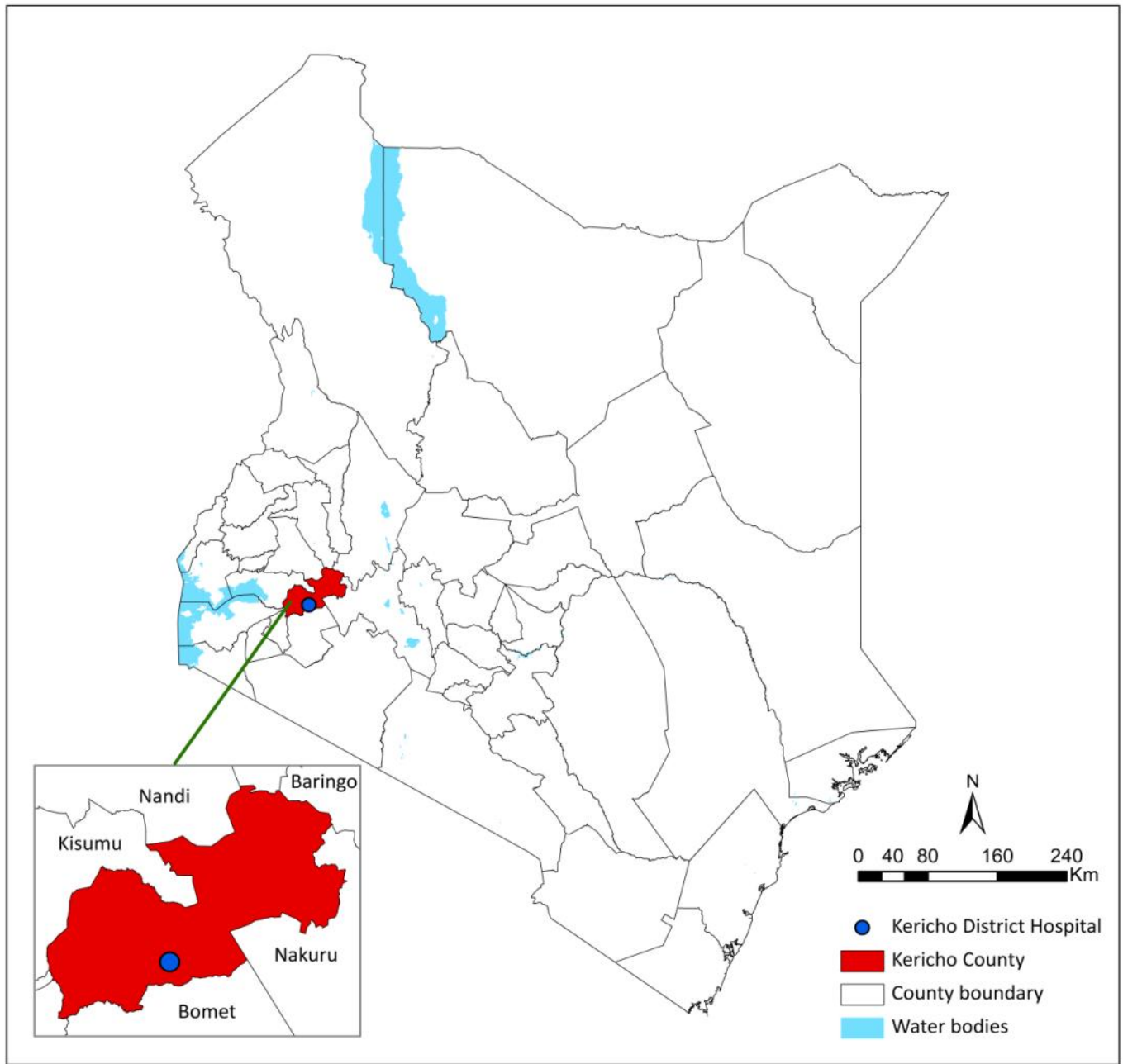

Figure 1

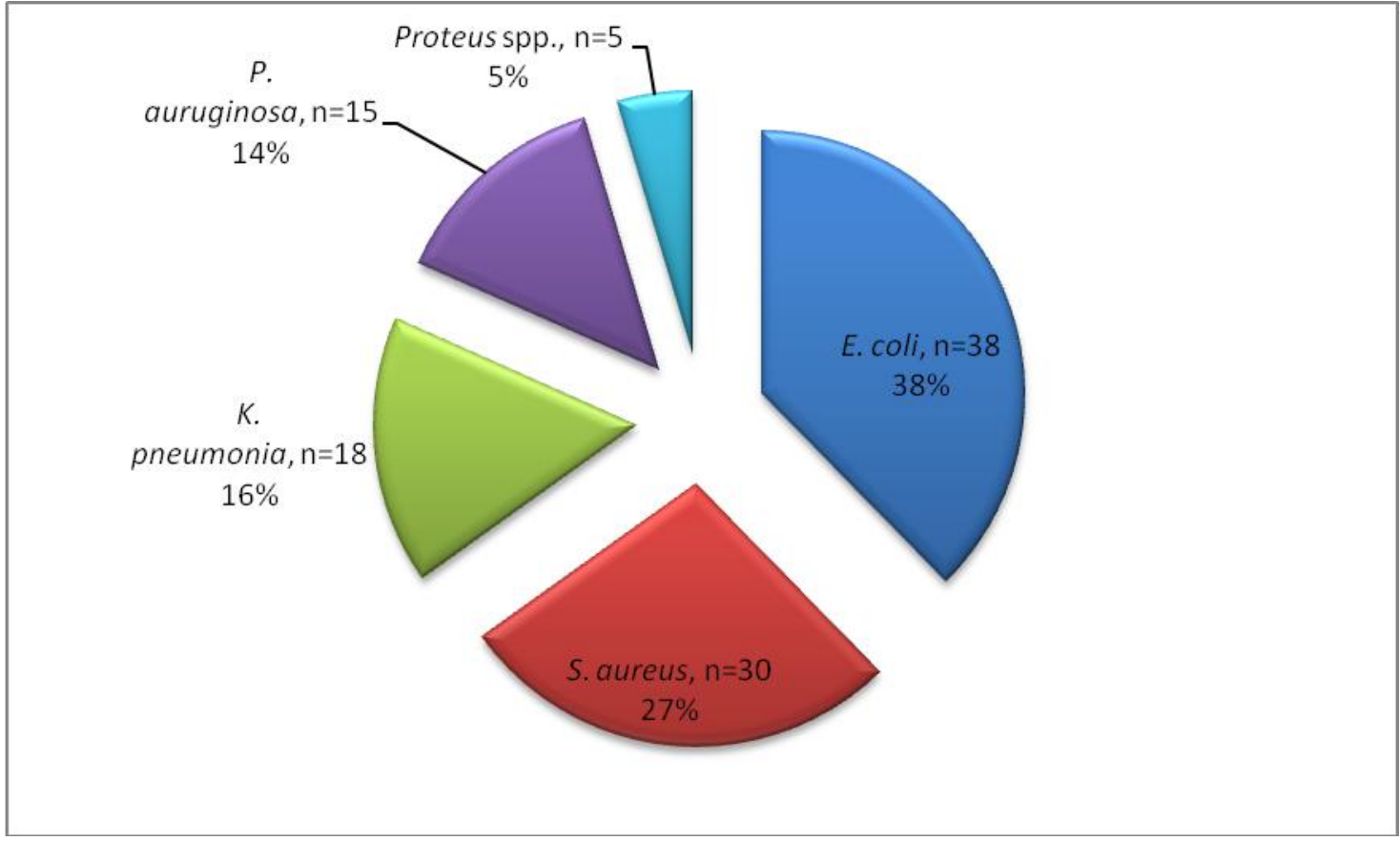

Figure 2

Volume 5 Issue 1, January 2016

www.ijsr.net 


\section{International Journal of Science and Research (IJSR) \\ ISSN (Online): 2319-7064}

Index Copernicus Value (2013): 6.14 | Impact Factor (2014): 5.611

\section{Tables}

Table 1: Antimicrobial Susceptibility of E. coli Clinical Isolates ( $\mathrm{n}=22)$ by Disc Diffusion on Females with UTI from Kericho District Hospital

\begin{tabular}{|c|c|c|c|c|c|c|}
\hline \multirow{2}{*}{ Antimicrobial Agent tested } & \multicolumn{2}{|c|}{ Zone of diameter nearest whole mm } & \multirow{2}{*}{ Resistance } & \multirow{2}{*}{ Intermediate } & \\
\cline { 2 - 5 } & $\mathbf{R}$ & $\mathbf{I}$ & $\mathbf{S}$ & & $3(13.6 \%)$ \\
\hline Trimethoprin-sulfamethoxazole & $<10$ & $11-15$ & $>16$ & $16(72.7 \%)$ & $3(13.6 \%)$ \\
\hline Gentamicin & $<12$ & $13-14$ & $>15$ & $12(54.4 \%)$ & $3(13.6 \%)$ \\
\hline Amikacin & $<14$ & $15-16$ & $>17$ & $2(9.1 \%)$ & $2(9.1 \%)$ & $18(81.8 \%)$ \\
\hline Ceftriaxone & $<19$ & $20-22$ & $>23$ & $12(54.4 \%)$ & $4(18.2 \%)$ & $6(27.3 \%)$ \\
\hline Ciprofloxacin & $<10$ & $21-30$ & $\geq 31$ & $9(40.9 \%)$ & $6(27.3 \%)$ & $3(13.6 \%)$ \\
\hline Cefoxitin & $<14$ & $15-17$ & $>18$ & $12(54.4 \%)$ & $7(31.8 \%)$ \\
\hline Cefepim & $<14$ & $15-17$ & $>18$ & $10(45.5 \%)$ & $5(22.7 \%)$ & $7(31.8 \%)$ \\
\hline Imipenem & $<19$ & $20-22$ & $>23$ & $1(4.5 \%)$ & 0 \\
\hline Ampicillin & $<13$ & $14-16$ & $>17$ & $19(86.4 \%)$ & $1(4.5 \%)$ \\
\hline Amoxicillin-clavulanic acid & $<13$ & $14-17$ & $\geq 18$ & $20(90.9 \%)$ & $21(95.5 \%)$ \\
\hline
\end{tabular}

Key: R- Resistance; I- Intermediate; S- Sensitive

Table 2: Antimicrobial Susceptibility Profile of $E$. coli Clinical Isolates $(n=16)$ by Disc Diffusion on Males with UTI from Kericho District Hospital

\begin{tabular}{|l|l|l|l|c|c|c|}
\hline \multirow{2}{*}{ Antimicrobial Agent tested } & \multicolumn{2}{|c|}{ Zone of diameter nearest whole mm } & \multirow{2}{*}{ Resistance } & Intermediate & \multirow{2}{*}{ Sensitive } \\
\cline { 2 - 6 } & \multicolumn{2}{|c|}{$\mathrm{R}$} & $\mathrm{I}$ & $\mathrm{S}$ & & \\
\hline Trimethoprin-sulfamethoxazole & $<10$ & $11-15$ & $>16$ & $15(93.75 \%)$ & 0 & $1(6.25 \%)$ \\
\hline Gentamicin & $<12$ & $13-14$ & $>15$ & $8(50 \%)$ & $2(12.5 \%)$ & $6(37.5 \%)$ \\
\hline Amikacin & $<14$ & $15-16$ & $>17$ & 0 & $2(12.5 \%)$ & $14(87.5 \%)$ \\
\hline Ciprofloxacin & $<19$ & $20-22$ & $>23$ & $10(62.5 \%)$ & $3(18.75 \%)$ & $3(18.75 \%)$ \\
\hline Ceftriaxone & $<10$ & $21-30$ & $\geq 31$ & $9(56.25 \%)$ & $3(18.75 \%)$ & $4(25 \%)$ \\
\hline Cefoxitin & $<14$ & $15-17$ & $>18$ & $10(62.5 \%)$ & $2(12.5 \%)$ & $4(25 \%)$ \\
\hline Cefepim & $<14$ & $15-17$ & $>18$ & $9(56.25 \%)$ & $2(12.5 \%)$ & $5(31.25)$ \\
\hline Imipenem & $<19$ & $20-22$ & $>23$ & 0 & 0 & $16(100 \%)$ \\
\hline Ampicillin & $<13$ & $14-16$ & $>17$ & $16(100 \%)$ & 0 & 0 \\
\hline Amoxicillin-clavulanic acid & $<13$ & $14-17$ & $\geq 18$ & $16(100 \%)$ & 0 & 0 \\
\hline
\end{tabular}

Key: R- Resistance; I- Intermediate; S- Sensitive

Table 3: Gender of Patient in Relation to Pathogenic Microorganism Isolated

\begin{tabular}{|l|l|l|l|}
\hline \multirow{2}{*}{ Bacterial isolates } & \multicolumn{2}{|c|}{ Gender of Patients } & \multirow{2}{*}{ Total } \\
\cline { 2 - 3 } & \multicolumn{1}{|c|}{ Female } & \multicolumn{1}{|c|}{ Male } & \\
\hline E. coli & $22(20.8 \%)$ & $16(15.1 \%)$ & $38(38.8 \%)$ \\
S. aureus & $20(18.9 \%)$ & $11(10.4 \%)$ & $31(29.2 \%)$ \\
K. pneumoniae & $12(11.3 \%)$ & $6(5.7 \%)$ & $18(17.0 \%)$ \\
P. aeruginosa & $11(10.4 \%)$ & $4(3.8 \%)$ & $15(14.2 \%)$ \\
P. mirabilis & $3(2.8 \%)$ & $1(0.9 \%)$ & $4(3.8 \%)$ \\
\hline Total & $\mathbf{6 8}(\mathbf{6 4 . 2 \% )}$ & $\mathbf{3 8 ( 3 5 . 8 \% )}$ & $\mathbf{1 0 6}(\mathbf{1 0 0} \%)$ \\
\hline
\end{tabular}

